\title{
Cervical Intraepithelial Neoplasia Managed With Classical Homeopathy: A Case Report
}

\author{
Seema Mahesh ${ }^{1}$, Olga Habchi ${ }^{2}$, and George Vithoulkas ${ }^{3}$ \\ ${ }^{1}$ Taylor's University - Lakeside Campus \\ ${ }^{2}$ Modern Medical Consultation Center \\ ${ }^{3}$ University of the Aegean
}

October 18, 2021

\begin{abstract}
We present the case of 33-year-old woman diagnosed with low to high grade squamous intraepithelial neoplasia that benefited with individualized classical homeopathy. The outcomes were resolution of the pre-malignant condition and the HPV infection, preventing the use of invasive procedures that were otherwise deemed necessary.
\end{abstract}

\section{Cervical Intraepithelial Neoplasia Managed With Classical Homeopathy: A Case Report}

Seema Mahesh ${ }^{1}$, Olga Habchi², George Vithoulkas ${ }^{3,4}$

1. School of Medicine, Faculty of Health and Medical Sciences, Taylor's University, Malaysia

2. The Modern Medical Consultation Centre, Dubai, UAE.

3. Postgraduate Doctors' Training Institute, Health Care Ministry of the Chuvash Republic, Cheboksary, Russian Federation.

4. International Academy of Classical Homeopathy, Alonissos, Greece.

${ }^{*}$ Corresponding author

School of Medicine, Faculty of Health and Medical Sciences, Taylor's University, Subang Jaya, Malaysia Phone: +60 123809077; email: bhatseema@hotmail.com

Running title: Cervical intraepithelial neoplasia, a homeopathic case report.

\section{Abstract:}

We present the case of 33-year-old woman diagnosed with low to high grade squamous intraepithelial neoplasia that benefited with individualized classical homeopathy. The outcomes were resolution of the premalignant condition and the HPV infection, preventing the use of invasive procedures that were otherwise deemed necessary.

Keywords : Cervical Intraepithelial Neoplasia, uterine cervical neoplasm, homeopathy, Low- High Grade Squamous Intraepithelial Lesions.

Key Clinical Message: Individualized classical homeopathy needs to be investigated for its relevance in treatment of cervical intraepithelial neoplasia with high risk of human papilloma virus infection, as the benefit was demonstrated in the case presented here.

\section{Abbreviations:}


CIN - Cervical intraepithelial neoplasia

HPV - Human Papillomavirus

hr HPV - high risk human papillomavirus

DNA - Deoxyribonucleic acid

ASC - Atypical Squamous Cells

ASC-US - Atypical Squamous Cells of Undetermined Significance

ASC-H - Atypical Squamous Cells - cannot exclude HSIL

LSIL - Low-grade Squamous Intraepithelial Lesion

HSIL - High-grade Squamous Intraepithelial Lesion

WHO - World Health Organisation

Pap test - Papanicolaou test

LLETZ - Large Loop Excision of the Transformation Zone

\section{INTRODUCTION:}

Cervical cancer is the fourth most common malignancy of the female reproductive system with over half a million women diagnosed, and over 300,000 deaths attributed to it globally each year ${ }^{1,2}$. The important risk factors in the genesis of cervical cancer are early coitarche, infection with high-risk HPV (hr HPV), other sexually transmitted infections, age $>30$ years, multiparity, multiple sexual partners and compromised host defense ${ }^{3,4}$. There are over 40 types of hr HPV identified as inhabiting the female genital tract that can potentially cause cervical cancer ${ }^{5,6}$. Cervical cancer has a long precancerous period, during which it may be detected and even effectively treated ${ }^{6}$.

The Bethesda system classifies a continuum of cytological abnormalities of the premalignant lesion in the Pap smear test. This nomenclature has replaced the earlier term Cervical Intraepithelial Neoplasia (CIN I, II and III, progressively riskier for developing cancer) with Squamous Intraepithelial Neoplasia (SIL), categorizing them into (a) Atypical Squamous Cells (ASC)-indicator of HPV infection, (b) Low grade Squamous Intraepithelial Lesion (LSIL) - cervical cells show changes that are mildly abnormal (c) High grade Squamous Intraepithelial Lesion (HSIL) cervical cells with severe changes. The ASC category is further divided into Atypical squamous cells of undetermined significance (ASC-US) and Atypical squamous cells - cannot exclude HSIL (ASC-H) $)^{6-8}$.

HPV vaccinations, local ablative methods like cryotherapy and cold coagulation, excisional methods such as large loop excision of the transformation zone (LLETZ), cone excision and hysterectomy are the approaches followed by conventional medicine as prevention and treatment modalities, but they seem to have unfavorable effect especially on the further reproductive outcomes, even when treated with conserving fertility as the goal ${ }^{9}$. This is of significance as the average age of women undergoing these treatments coincides with the average age of first child globally ${ }^{9}$.

Previous case reports of homeopathy in cancer cases have provided evidence for beneficial outcomes from classical homeopathy ${ }^{10}$. Here, we present a case of LSIL treated with homeopathy. The approach not only helped the pre-invasive disease but also improved the comorbidities.

\section{METHODS:}

\section{Case report:}

Case presentation: A 33-year-old Indian woman, presented to the homeopath after being diagnosed with LSIL-HSIL. 
History of presenting complaints: On 26/08/2019, she underwent a PAP smear test which revealed ASC-US cytology (Fig. 1). Further when screened for HPV DNA, the patient tested positive for HPV $(18,52)$ high risk type on 03/09/2019 (Fig. 1).

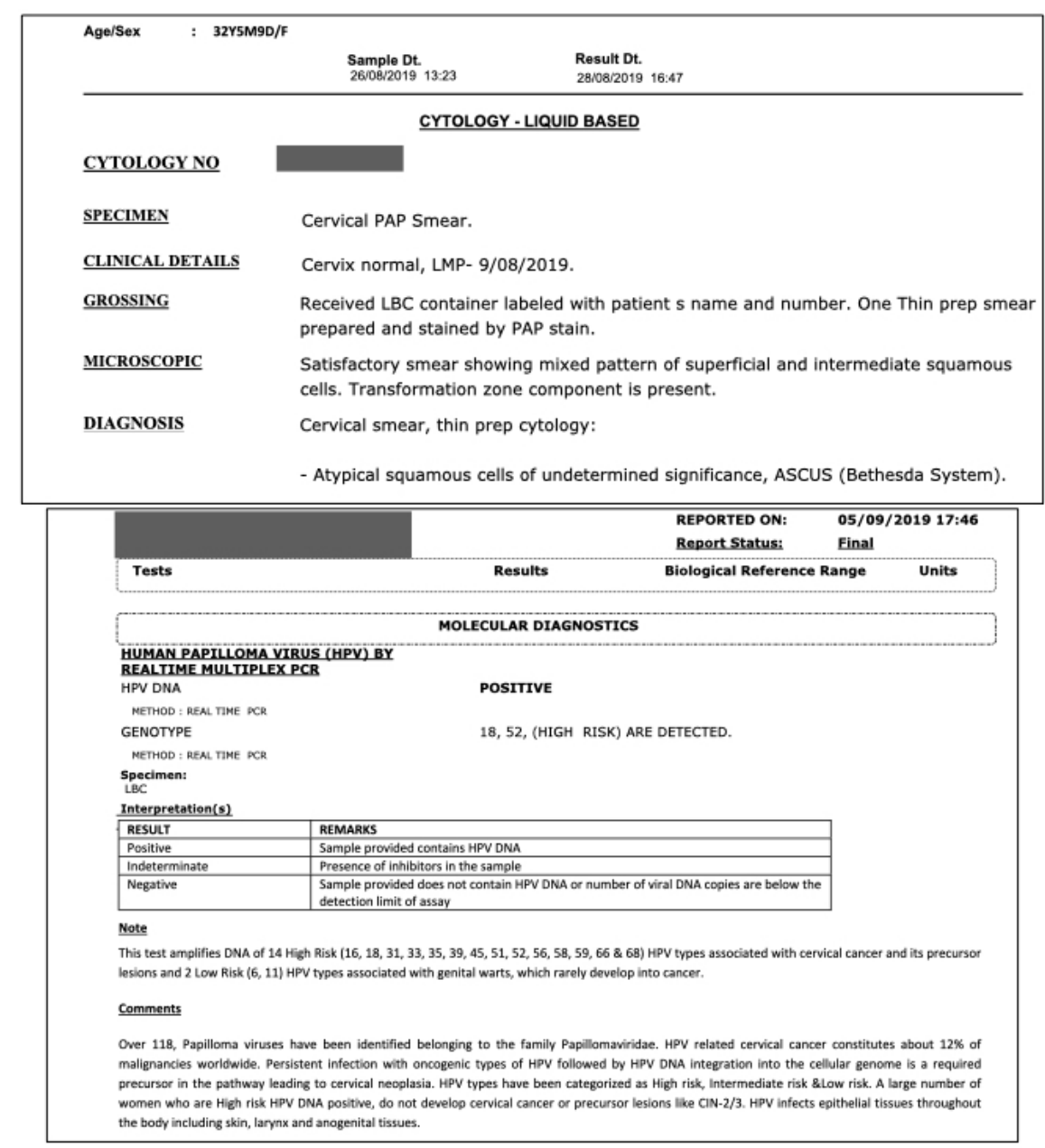

Fig 1. Pap smear test report of 26/08/2019 and HPV DNA test report of 03/09/2019.

On 18/09/2019, cervical biopsy revealed a low grade squamous intraepithelial lesion with focal high grade squamous intraepithelial lesion CIN I- CIN II (Fig. 2) indicating that the condition had progressed. On 10/05/2020, cervical Pap smear test showed low grade intraepithelial lesion CIN I (Fig.2). 


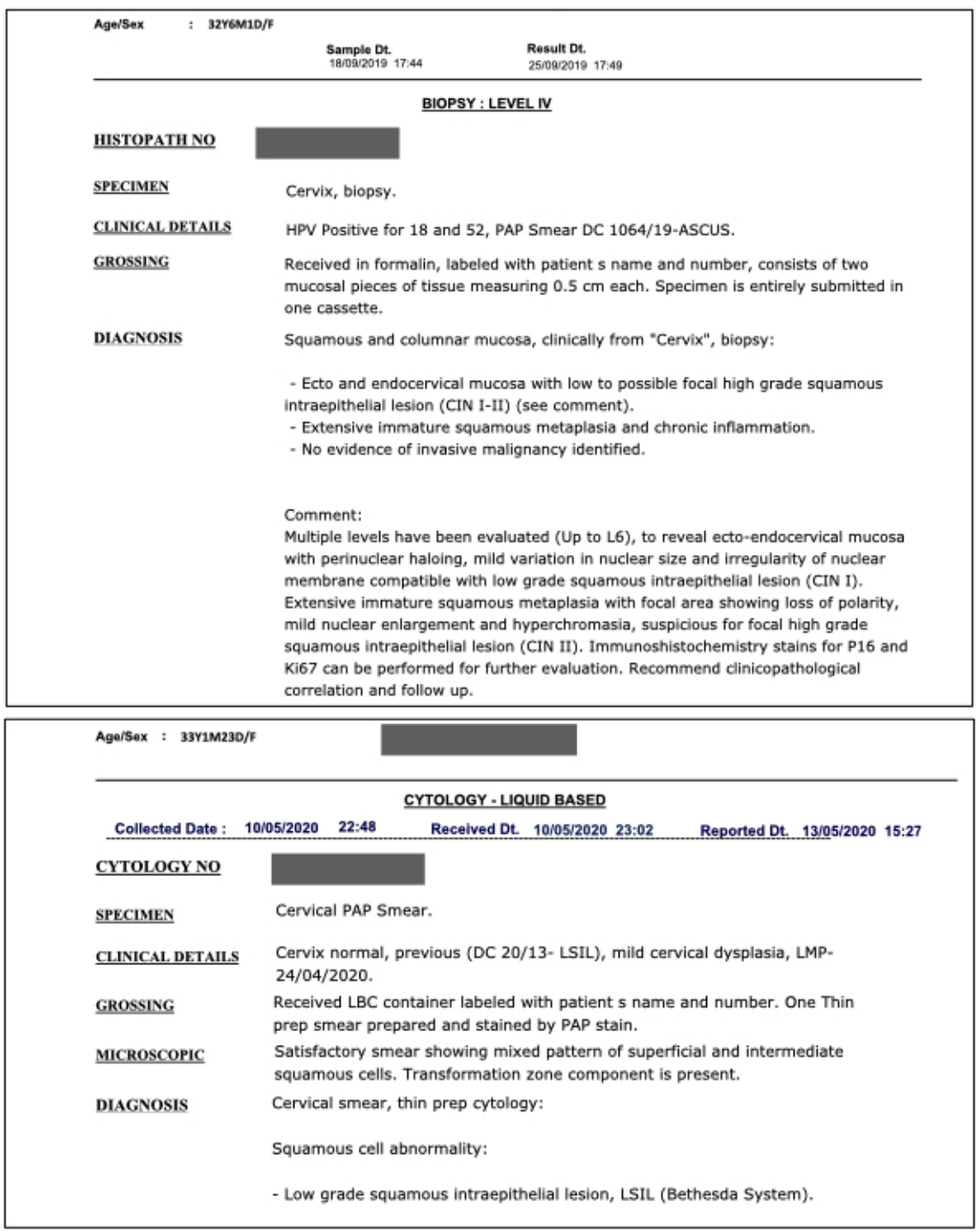

Fig 2. Biopsy report of 18/09/2019 and Pap smear report of 10/05/2020.

Conventional treatment advice: Patient was advised to undergo conization.

Due to fear of the adverse consequences that cervical conization might have on her future fertility and obstetric outcome, patient chose to approach homeopathy for a non-invasive therapeutic intervention.

Homeopathic consultation: The initial anamnesis of the case took place on 18/05/2020. Along with the said diagnosis, patient had PCOS, menstrual cycles every 35-36 days; nodular, facial acne and hair fall. Patient was very anxious about her health.

Past medical history: Bronchial asthma with breathing difficulty in humid climate and atopic dermatitis on flexor surface of joints in childhood, treated conventionally.

Family history: Father had hypertension, bronchial asthma and eczema. There was a history of bronchial asthma and eczema in his siblings. The mother was healthy.

Obstetrics and gyneacological history: Menarche at 11 years. Nullipara. Menstrual cycle every 33-36 days. 
Flow is scanty to normal.

Diagnosis: Low-High grade squamous intraepithelial lesion CIN I-CIN II (ICD 10 - R87.612) ${ }^{11}$

Homeopathic intervention:

After thorough case taking, Pulsatilla nigricans $200 \mathrm{CH}$ was prescribed in diluted form for 1 month (one tablespoon per day). The remedy was selected on the basis of principles of classical homeopathy, which includes an integral picture of the physical and mental/emotional suffering.

\section{RESULTS:}

The patient underwent homeopathic therapy for a period of approximately 4 months, during which a simultaneous amelioration of comorbidities such as irregular menstrual cycles, acne and eczema were observed along with the resolution of Low-High grade squamous intraepithelial lesion.

\section{Follow up :}

The follow up of the case with cytological and symptomatic observations are presented in table 1 .

Table 1: Follow up of the case

\begin{tabular}{|c|c|c|c|}
\hline Date & $\begin{array}{l}\text { Detailed symp- } \\
\text { toms/observations }\end{array}$ & $\begin{array}{l}\text { Gynecological/ } \\
\text { Cytological findings }\end{array}$ & $\begin{array}{l}\text { Homeopathic } \\
\text { prescription: }\end{array}$ \\
\hline $22^{\text {nd }}$ June 2020 & $\begin{array}{l}\text { Patient is still anxious } \\
\text { about her condition. } \\
\text { Facial acne got worse. } \\
\text { Dry eczematous rashes } \\
\text { on fingers started } \\
\text { appearing, which was an } \\
\text { old complaint during } \\
\text { childhood. Patient was } \\
\text { advised to not intervene } \\
\text { in any way with the skin } \\
\text { manifestation. }\end{array}$ & $\begin{array}{l}\text { Cervical erosion, CIN I } \\
- \text { CIN II HPV } 18,52\end{array}$ & $\begin{array}{l}\text { Silicea } 200 \mathrm{CH} \text { was given } \\
\text { in diluted form, one } \\
\text { tablespoon every day for } \\
1 \text { month. }\end{array}$ \\
\hline $22^{\text {nd }}$ July 2020 & $\begin{array}{l}\text { Folliculitis over abdomen } \\
\text { appeared and resolved in } \\
3 \text { days. Acne is better, } \\
\text { scar marks seen. Hair fall } \\
\text { has reduced. Dry eczema } \\
\text { over finger has reduced. } \\
\text { Menstrual cycles are } \\
\text { regular. }\end{array}$ & $\begin{array}{l}\text { Size of cervical erosion } \\
\text { has reduced. }\end{array}$ & $\begin{array}{l}\text { Calcarea carbonica } \\
200 \mathrm{CH} \text { was given in } \\
\text { diluted form, one } \\
\text { tablespoon for } 1 \text { month. }\end{array}$ \\
\hline $3^{\text {rd }}$ September 2020 & $\begin{array}{l}\text { Patient developed boils } \\
\text { over back. Sleep is very } \\
\text { refreshing now. No acne } \\
\text { noted. Anxiety about } \\
\text { health - completely } \\
\text { better. Dry eczema on } \\
\text { hands persists with a } \\
\text { decreased intensity. }\end{array}$ & $\begin{array}{l}\text { No cervical erosion noted. } \\
\text { Cervix looks healthy. }\end{array}$ & $\begin{array}{l}\text { Calcarea carbonica } \\
200 \mathrm{CH} \text { was given in } \\
\text { diluted form for } 1 \text { month. }\end{array}$ \\
\hline
\end{tabular}


$26^{\text {th }}$ October 2020
Eczema has resolved. No acne. Menstrual cycles are regular, no menorrhagia noted.
Negative for intraepithelial lesion and malignancy. (Fig. 3)

HPV-DNA tested negative in November.

Outcome: The last pap smear performed on 26/10/2020 showed no signs of intraepithelial lesions, and the test for viral DNA done on 7/11/2020 detected no HPV DNA (Fig 3).

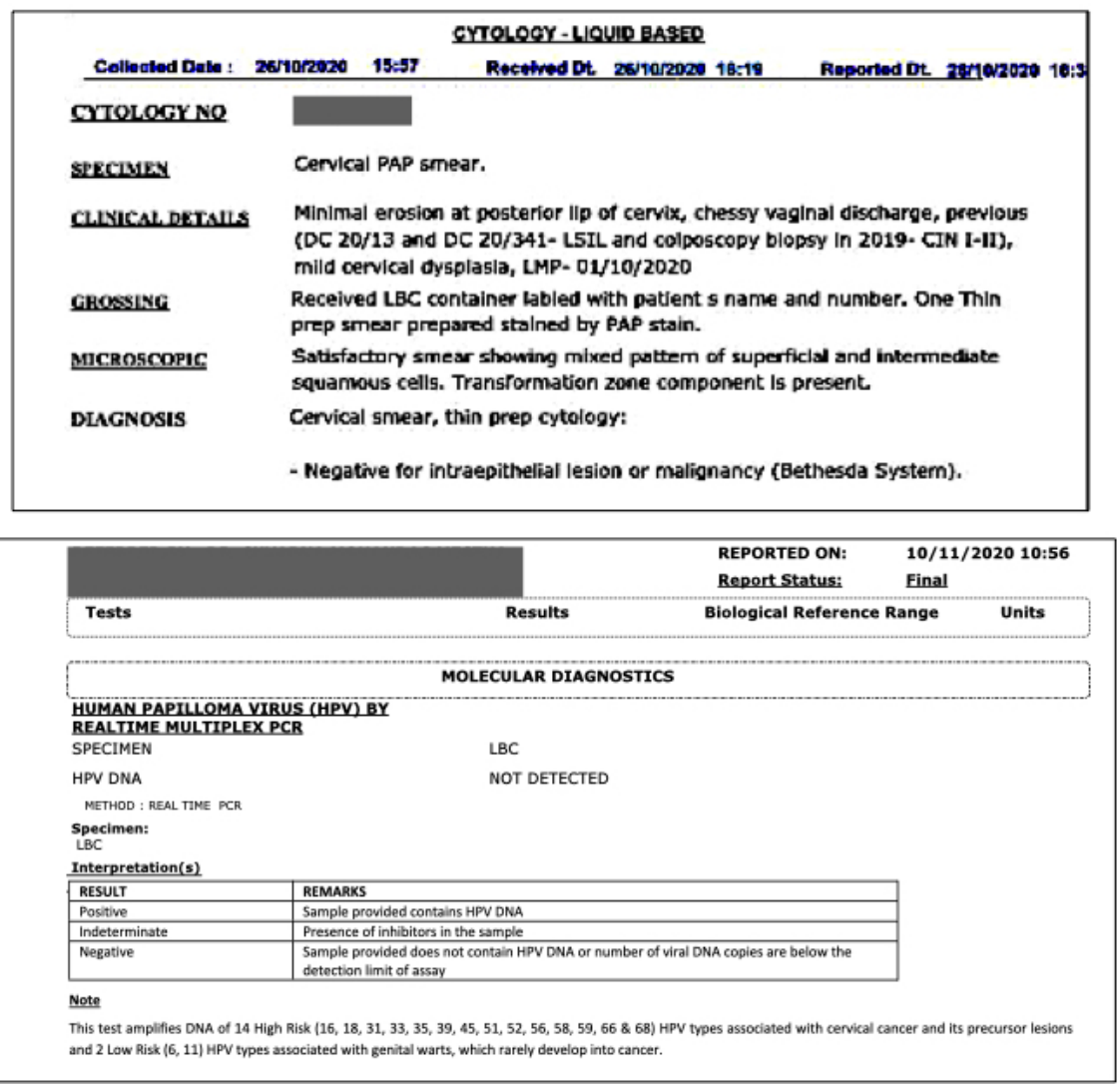

Fig 3. Pap smear report of 26/10/2020 and HPV DNA test report of 07/11/2020.

\section{Discussion:}

Classical homeopathy considers the presenting pathology along with the mental/emotional disturbances experienced by the patient in association with their hereditary influences and past diseases and treatments to synthesize an integrated picture of the diseased patient. This is then used to select the remedy that is indicated for that specific picture. Thus, personalized treatment is provided to every patient. As also observed in this case, the homeopathic remedies were selected for such a totality of physical, mental and emotional suffering along with the hereditary influences, and the outcome was favorable. Homeopathy has been shown to be beneficial in various cancerous conditions, but seldom in CIN and HPV ${ }^{10,12}$. Further, in this case, we see the most pertinent favorable prognostic sign with treatment - the return of a previously suppressed skin eruption. While evidence exists for the direct association of history of atopic dermatitis with cervical cancer ${ }^{13}$, the homeopathic perspective is different from this. When a patient is being treated for 
what is considered deeper pathology (such as CIN in this case), the return of a more superficial pathology (in this case, atopic dermatitis) that the patient had suffered from earlier in her life and which had been suppressed at that time, is considered a sure indication of improvement in the deeper pathology ${ }^{14}$. Here, it was corroborated by the biopsy and viral DNA analysis reports, which showed absence of CIN histology and HPV DNA after treatment. The causality assessment with Modified Naranjo Criteria for Homeopathy (MONARCH) yielded a score of 10/13, indicating strong causal relation of the effects to the treatment (Table 2).

Table 2. Modified Naranjo Criteria for Homeopathy (MONARCH) - for causality assessment.

\section{Criteria}

1. Was there an improvement in the main symptom or condition for which the homeopathic medicine was prescribed?

2. Did the clinical improvement occur within a plausible time frame relative to the drug intake?

3. Was there an initial aggravation of symptoms?

4. Did the effect encompass more than the main symptom or condition, i.e., were other symptoms ultimately improved or c

5. Did overall well-being improve?

6 (A) Direction of cure: did some symptoms improve in the opposite order of the development of symptoms of the disease?

6 (B) Direction of cure: did at least two of the following aspects apply to the order of improvement of symptoms: - from or

7. Did "old symptoms" (defined as non-seasonal and non-cyclical symptoms that were previously thought to have resolved)

8. Are there alternate causes (other than the medicine) that with a high probability could have caused the improvement? (

9. Was the health improvement confirmed by any objective evidence? (In this case by pap smear and viral DNA detection) 10. Did repeat dosing, if conducted, create similar clinical improvement?

Total

The homeopathic preparations that were prescribed here are what are referred to as "polychrest remedies" in the homeopathic materia medica. This implies that these remedies have a broad systemic influence and need to be selected by the totality of pathology, mental and emotional symptomatology considered together. The mechanism of their action is unknown, although they most likely work by enhancing immune system protection, as indicated by the numerous clinical benefits. ${ }^{10,15}$.

\section{Conclusions:}

This case of an Indian woman diagnosed with cervical intraepithelial neoplasia with high-risk human papillomavirus infection benefited with individualized classical homeopathy. Further scientific investigations to determine the relevance of this therapy in preventing overt cervical cancer in such cases is needed.

\section{Acknowledgement:}

The authors acknowledge the help of patient in consenting for publication and Dr Aaditi Lakshman for rendering technical help.

Statement of Ethics:Written consent was obtained from the patient for publication of case details.

\section{Conflict of Interest Statement:}

The authors have no conflicts of interest to declare.

\section{Funding Sources:}

No funding was obtained for this work.

\section{Authors' Contributions:}

$\mathrm{OH}$ is the primary physician who treated the patient and collected all the data, SM wrote the manuscript and obtained references and GV is the guide and guarantor of the work.

\section{References:}


1. Cohen PA, Jhingran A, Oaknin A, Denny L. Cervical cancer.Lancet. 2019;393(10167):169-182.

2. Buskwofie A, David-West G, Clare CA. A Review of Cervical Cancer: Incidence and Disparities. J Natl Med Assoc. 2020;112(2):229-232.

3. Jain MA, Limaiem F. Cervical Intraepithelial Squamous Cell Lesion. In: StatPearls. Treasure Island (FL): StatPearls Publishing

Copyright (C) 2021, StatPearls Publishing LLC.; 2021.

4. Torres-Poveda K, Ruiz-Fraga I, Madrid-Marina V, Chavez M, Richardson V. High risk HPV infection prevalence and associated cofactors: a population-based study in female ISSSTE beneficiaries attending the HPV screening and early detection of cervical cancer program. BMC Cancer. 2019;19(1):1205.

5. Long W, Yang Z, Li X, et al. HPV-16, HPV-58, and HPV-33 are the most carcinogenic HPV genotypes in Southwestern China and their viral loads are associated with severity of premalignant lesions in the cervix. Virol J. 2018;15(1):94-94.

6. Kyrgiou M, Shafi MI. Colposcopy and cervical intraepithelial neoplasia. Obstetrics, Gynaecology \& Reproductive Medicine.2014;24(7):204-214.

7. Ndifon CO, Al-Eyd G. Atypical Squamous Cells of Undetermined Significance (ASCUS). StatPearls [Internet]. 2020.

8. Tsikouras $\mathrm{P}$, Zervoudis S, Manav B, et al. Cervical cancer: screening, diagnosis and staging. $J$ buon. 2016;21(2):320-325.

9. Kyrgiou M, Athanasiou A, Kalliala IEJ, et al. Obstetric outcomes after conservative treatment for cervical intraepithelial lesions and early invasive disease. Cochrane Database Syst Rev.2017;11(11):Cd012847.

10. Mahesh S, Mallappa M, Vithoulkas G. Embryonal carcinoma with immature teratoma: A homeopathic case report. Complementary medicine research. 2018;25(2):117-121.

11. World Health Organization. International classification of diseases and related health problems, 10th revision.http://wwwwhoint/classifications/apps/icd/icd10online.2007.

12. Gaertner K, Lüer SC, Frei-Erb M, von Ammon K. Complementary individual homeopathy in paediatric cancer care: A case series from a University Hospital, Switzerland. Complementary Therapies in Medicine. 2018;41:267-270.

13. Morgan TK, Hanifin J, Mahmood M, et al. Atopic Dermatitis Is Associated With Cervical High Risk Human Papillomavirus Infection. Journal of Lower Genital Tract Disease. 2015;19(4).

14. Vithoulkas G, Carlino S. The "continuum" of a unified theory of diseases. Medical Science Monitor. $2010 ; 16(2)$.

15. Vithoulkas G, Mahesh S, Mallappa M. Gangrene: Five case studies of gangrene, preventing amputation through Homoeopathic therapy.Indian Journal of Research in Homoeopathy. 2015;9(2):114.

\section{Table Legends:}

Table 1. Follow up of the case.

Table 2. Modified Naranjo Criteria For Homeopathy (MONARCH) - for causality assessment.

\section{Figure Legends:}

Fig 1. Pap smear test report of 26/08/2019 and HPV DNA test report of 03/09/2019.

Fig 2. Biopsy report of 18/09/2019 and Pap smear report of 10/05/2020.

Fig 3. Pap smear report of 26/10/2020 and HPV DNA test report of 07/11/2020. 